\title{
Genetic causes of isolated short stature
}

\author{
Gabriela A. Vasques ${ }^{1,2}$, Nathalia L. M. Andrade ${ }^{1,2}$, Alexander A. L. Jorge 1,2
}

${ }^{1}$ Unidade de Endocrinologia Genética (LIM25), Hospital das Clínicas, Faculdade de Medicina, Universidade de São Paulo (HCFMUSP), São Paulo, SP, Brasil ${ }^{2}$ Unidade de Endocrinologia do Desenvolvimento, Laboratório de Hormônios e Genética Molecular (LIM42), Hospital das Clínicas, Faculdade de Medicina, Universidade de São Paulo (HCFMUSP), São Paulo, SP, Brasil

Correspondence to: Alexander A. L. Jorge Faculdade de Medicina,

Universidade de São Paulo (LIM-25)

Av. Dr. Arnaldo, 455,

$5^{\circ}$ andar, sala 5340

01246-903 - São Paulo, SP, Brasil

alexj@usp.br

Received on Nov/29/2018

Accepted on Feb/22/2019

DOI: $10.20945 / 2359-3997000000105$

\begin{abstract}
Short stature is a common feature, and frequently remains without a specific diagnosis after conventional clinical and laboratorial evaluation. Longitudinal growth is mainly determined by genetic factors, and hundreds of common variants have been associated to height variability among healthy individuals. Although isolated short stature may be caused by the combination of variants, with a deleterious impact on the growth of individuals with polygenic inheritance, recent studies have pointed out some monogenic defects as the cause of the growth disorder observed in nonsyndromic children. The majority of these defects are in genes related to the growth plate cartilage and in the growth hormone $(\mathrm{GH})$ - insulin-like growth factor 1 (IGF-1) axis. Affected patients usually present the mildest spectrum of some forms of skeletal dysplasia, or subtle abnormalities of laboratory tests, suggesting hormonal resistance or insensibility. The lack of specific characteristics, however, does not allow formulation of a definitive diagnosis without the use of broad genetic studies. Thus, molecular genetic studies including panels of genes or exome analysis will become essential in investigating and identifying the causes of isolated short stature in children, with a crucial impact on treatment and follow-up. Arch Endocrinol Metab. 2019;63(1):70-8
\end{abstract}

Keywords

Short stature; growth; growth cartilage; growth hormone

\section{INTRODUCTION}

S hort stature is defined as a condition characterized by height more than 2 standard deviation scores below the mean observed in age and sex control population (height SDS $<-2$ ) $(1)$. Based on this definition, short stature affects $2.3 \%$ of children, and is a matter of concern for many parents seeking medical attention. Although growth disorder may be a clinical presentation of an underlying disease, in around 70\% of the cases, short stature is not associated with any clinical and laboratory evidence that justify growth impairment (2). These children are usually classified as having constitutional or idiopathic short stature (ISS) (3). In this review, we also used the term isolated short stature, in view of the growing number of monogenic conditions that explain the short stature phenotype in nonsyndromic children.

Height is one of the human traits with a higher degree of heritability (> 80\%), which means that genetic variability is the main determinant of stature (4). Up to date, more than 600 common variants (with allele frequencies greater than $1 \%$ ) distributed across more than 400 regions of the genome have been independently associated with height (5). The impact of each identified common variant on stature is small (around 1-4 mm). More recently, studies have pointed out that rare variants (frequency $<1 \%$ ) may exert an effect on height variability 10 to 20 times greater than that exert by common variants (about $20 \mathrm{~mm}$ per allele). Many of these common and rare variants are in genes associated with syndromic growth disorders or in genes involved in the development of the growth cartilage (6).

Since short stature is a common clinical presentation, it is widely accepted that it is caused by common variants with polygenic inheritance $(7,8)$. However, recent studies have challenged this dogma, and proposed that many of the children classified as ISS could instead have a monogenic defect. A part of this group would represent the mildest spectrum of phenotypic variability of syndromic conditions $(9,10)$. For example, there are short stature individuals harboring pathogenic variants in genes responsible for the Noonan syndrome who do not present any of the other phenotypic alterations that 
would allow the recognition of this condition clinically (11). Additionally, genes that regulate the growth plate and that had already been associated with skeletal dysplasias were recently pointed as responsible for some cases of ISS (12-16). This review provides an update on monogenic causes of isolated short stature.

\section{GENES THAT REGULATE GROWTH PLATE}

Endochondral ossification is a complex process which occurs in the growth plate to promote bone elongation and consequent increase in height. It involves proliferation, hypertrophy and senescence of chondrocytes and also cartilage matrix synthesis (17). Paracrine and autocrine factors are the main regulators of endochondral ossification and defects in genes that encode or disrupt these factors (summarized in Table 1) have been associated with ISS. Each of these genes is responsible for a small proportion of cases (up to $2 \%$ ), but this proportion may be significantly higher in familial short stature. Defects in genes that regulate growth plate, inherited in an autosomal dominant manner, cause a variable phenotype in terms of degree of short stature and body proportions. The atypical radiological findings do not allow the precise diagnosis and some of the patients are recognized as having a subclinical skeletal dysplasia.

\section{SHOX}

The short stature homeobox (SHOX) gene is located in the pseudoautosomal region 1 of both sex chromosomes and is expressed in growth cartilage, especially in hypertrophic chondrocytes. The role of the SHOX gene as a regulator of the growth plate has not been fully understood. It is known that SHOX is a transcription factor that increases $N P P B$ and inhibits FGFR3 expression, respectively (Figure 1A).
Both effects stimulate and coordinate chondrocytes proliferation and differentiation in order to promote longitudinal growth. In addition, SHOX interacts with the SOX trio (SOX9, SOX5 and SOX6 genes), which has an important role in cartilage matrix synthesis (18). The causative relation between SHOX defects and ISS was first described in 1997 (12). Since then, SHOX haploinsufficiency has become the main recognized monogenic cause of short stature, being responsible for $2.6 \%$ of the nonsyndromic cases of short stature. Homozygous defects in SHOX gene cause Langer mesomelic dysplasia, a rare skeletal dysplasia with severe short stature and limb aplasia or hypoplasia of the ulna and fibula. Heterozygous SHOX haploinsufficiency causes phenotypes that range from isolated short stature to the complete picture of the Leri-Weill dyschondrosteosis (LWD), a skeletal dysplasia characterized by mesomelia and Madelung deformity (i.e. shortening and bowing of the radius with dorsal subluxation of the distal ulna) (19). Around $80 \%$ of reported SHOX defects are deletions involving the gene or regulatory regions, with the remaining ones being point mutations. Although no genotypephenotype correlation has been identified in individuals with $S H O X$ deletions encompassing exons and point mutations, deletion in downstream SHOX enhancer have been associated with a milder phenotype (18).

Abnormal body proportion, defined by the [sitting height $] /$ height $]$ ratio for age and $\operatorname{sex}(\mathrm{SH} / \mathrm{H}$ SDS $)>2$, is present in the vast majority of children with isolated short stature caused by SHOX haploinsufficiency (20). The degree of short stature is variable, and the mean growth deficit of affected individuals is of around 12 $\mathrm{cm}$, which means that there are carriers with height within the normal range.

A reasonable clinical selection criterion to screen for SHOX defects in a child with isolated short stature is

Table 1. Genes involved in the endochondral ossification process that are associated with isolated short stature

\begin{tabular}{lccl}
\hline Gene & $\begin{array}{c}\text { First report in patient } \\
\text { classified as ISS }\end{array}$ & Frequency in ISS (\%) & Additional common findings \\
\hline SHOX & 1997 & $2.6(1.1$ to 22.2) & Mild abnormal body proportion, family member with Madelung deformity \\
NPR2 & 2013 & 1.8 to $6\left(13.6^{*}\right)$ & Nonspecific skeletal abnormalities, as short metacarpals \\
NPPC & 2018 & $\mathrm{NA}$ & Two families described with brachydactyly \\
ACAN & 2014 & 1.4 & Accelerated bone maturation and early-onset osteoarthritis \\
IHH & 2018 & 3.4 & Shortening of the middle phalanx of the 5th finger \\
FGFR3 & 2015 & $\mathrm{NA}$ & Only one family described with normal body proportion \\
\hline
\end{tabular}

* Familial cases; NA: not available; ISS: idiopathic short stature. 
the presence of abnormal body proportion, especially if the phenotype of disproportional short stature segregates in an autosomal dominant manner and/or there is a family member with Madelung deformity. Particular attention should be given to the regulatory regions of SHOX gene, since deletions located outside the coding region are more commonly associated with short stature without other specific findings.

\section{NPR2 and NPPC}

The C-type natriuretic peptide (CNP) and its receptor (NPR-B) are important regulators of the endochondral ossification process (21). CNP and NPR-B are encoded by NPPC and NPR 2 genes, respectively. They are notably expressed in the hypertrophic zone of the growth plate. The CNP/NPR-B system stimulates chondrocyte proliferation and differentiation and synthesis of cartilage matrix in an autocrine/paracrine manner. The molecular mechanism that explains these actions is at least partially identified and involves the inhibition of the FGFR3 pathway (Figure 1B). After CNP binding to NPR-B, there is an intracellular accumulation of cyclic GMP (cGMP), that activates cGMP-dependent protein kinases I and II (cGKI and cGKII). cGKII inhibits the activation of RAF-1. Biallelic loss-of-function mutations in NPR2 cause acromesomelic dysplasia type Maroteaux (21). Heterozygous NPR2 mutations in a cohort of ISS children were first described in 2013 (13). Since then, other studies have replicated this finding and the prevalence of heterozygous NPR2 mutations in ISS patients has ranged from $1.8 \%$ to $13.6 \%$ (in familial cases) (22). Similar to what has been observed in patients with SHOX haploinsufficiency, carriers of NPR2 mutation have a variable degree of short stature and some carrier relatives presented height at the lower limit of the normal range. Abnormal body proportion $(\mathrm{SH} / \mathrm{H} \mathrm{SDS}>2)$ and nonspecific skeletal abnormalities, as short metacarpals (Figure 2A), were also observed among patients with NPR2 mutations. Due to the phenotypic heterogeneity, there is, at the moment, no clinical feature that enables establishing a criterion to select short stature patients for for NPR2 molecular-genetic screening.

More recently, heterozygous NPPC mutations have been identified in two families with ISS. In total, six NPPC carriers were identified, two being Brazilian and four Spanish. Their height SDS ranged from -4.3 to -2.3 and all of them also had small hands phenotype (16).

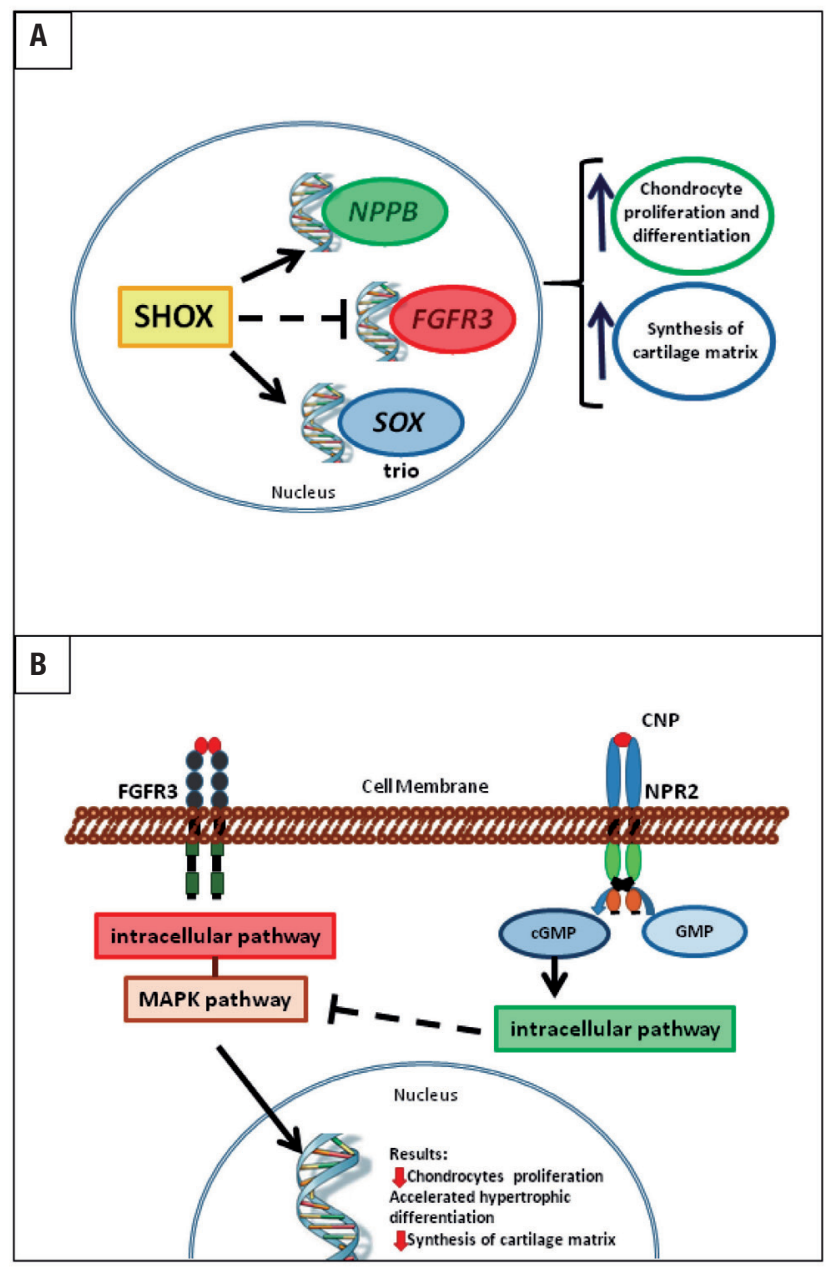

Figure 1. Schematic representation of chondrogenesis regulation by genes associated to isolated short stature phenotype. (A) SHOX is a transcriptional factor that enhances NPPB and SOX trio expression and inhibits FGFR3 expression. This leads to an increase in chondrocyte proliferation and differentiation and an increase in cartilage matrix synthesis. (B) CNP and FGF signaling pathways converge at the MAPK pathway. The opposite effect of CNP on FGFR3 pathway improves longitudinal bone growth by increasing chondrocyte proliferation and differentiation and cartilage matrix synthesis.

\section{ACAN}

The Aggrecan gene $(A C A N)$ encodes a proteoglycan present in the extracellular matrix. Aggrecan has a fundamental structural and functional role in the growth plate cartilage. Initially, $A C A N$ mutations were associated with two rare types of skeletal dysplasias, one with an autosomal dominant (Spondyloepiphyseal dysplasia, Kimberley type) and another with a recessive inheritance (Spondyloepimetaphyseal dysplasia, aggrecan type) (23). In 2014, heterozygous $A C A N$ mutations were identified as cause of short stature in three families with no skeletal findings suggestive of skeletal dysplasia. Children presented accelerated bone 


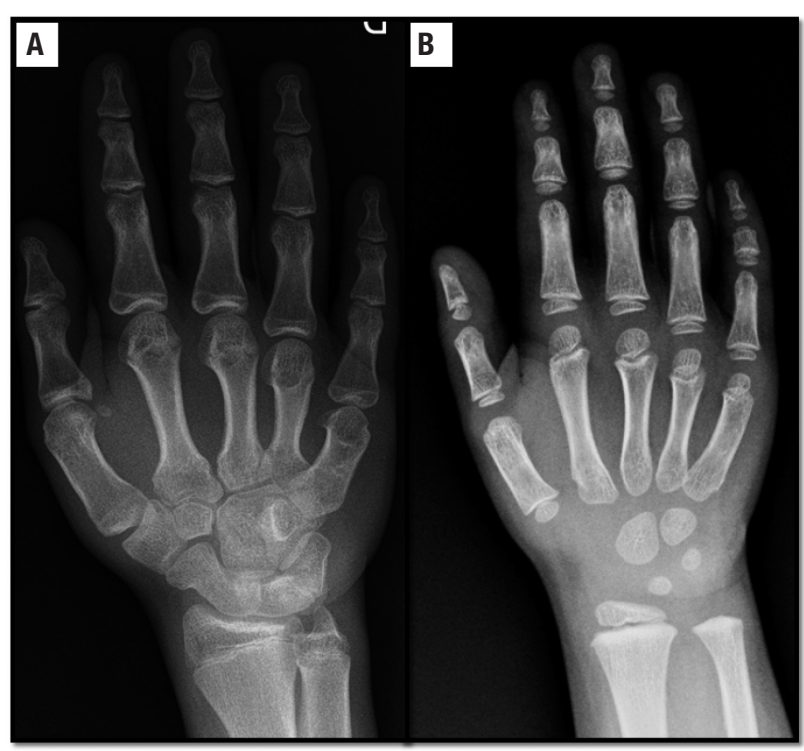

Figure 2. Hand radiographs of children carrying NPR2 and IHH mutations. (A) Hand radiograph of a patient with heterozygous mutation in NPR2. Shortening of metacarpal is clearly observed. (B) Hand radiograph of a child with heterozygous mutation in $I H H$ showing the shortening of the middle phalanx of the $5^{\text {th }}$ finger with cone-shaped epiphyses.

maturation, even before puberty, and some subjects had accompanying early-onset osteoarthritis (14). This dual phenotypic presentation occurs because aggrecan is a component of both growth plate and articular cartilage.

Since the first report, more than one hundred individuals from more than twenty families with autosomal dominant inherited short stature were identified as carriers of $A C A N$ mutations (24). Affected children seem to have growth impairment even before birth, and mutations in this gene were reported in a cohort of short children born small for their gestational age, mainly regarding birth length (25). The majority of children with $A C A N$ mutations have proportionate short stature with advanced bone age. Due to the poor pubertal spurt followed by early growth cessation, final height is still more compromised and adults present lower height SDS and, frequently, body disproportion. Other clinical features recognized in affected subjects are brachydactyly, mild midface hypoplasia, and flat nasal bridge. Some individuals present early-onset osteoarthritis, which appears until fourth decade of life and affects most commonly the knees, with a variable degree of severity (24). Whereas most children from cohorts of patients with ISS have delayed bone age, $A C A N$ mutation should be suspected in a short child with advanced bone age.
IHH

The Indian hedgehog gene $(I H H)$ is expressed in prehypertrophic chondrocytes of the growth plate, and codifies a key paracrine regulator of endochondral ossification, which coordinates chondrocytes proliferation and differentiation (26). Similar to what occurs with the other genes that regulate growth plate described above, IHH defects had already been recognized as a cause of two skeletal dysplasias. Homozygous $\mathrm{IHH}$ mutations cause acrocapitofemoral dysplasia, characterized by severe disproportionate short stature with cone-shaped epiphyses in hands and hips. Additionally, heterozygous mutations in $\mathrm{IHH}$ cause brachydactyly type $\mathrm{Al}$ (BDAl), characterized by a striking shortening of the middle phalanges, which can be fused with the terminal ones (27). Interestingly, short stature was not consistently reported in patients with BDAl (28).

In 2018, we described heterozygous $I H H$ mutations as a cause of the growth impairment in an ISS cohort (frequency of $3.4 \%$ ) (15). Our patients with heterozygous $I H H$ variants did not present classical features of $\mathrm{BDAl}$. The only recurrent radiological finding observed was a varying degree of shortening of the middle phalanx of the $5^{\text {th }}$ finger (Figure $2 \mathrm{~B}$ ), which is the defining feature of Brachymesophalangia - V (BMP-V). BMP-V was observed in $64.3 \%$ hand radiographs from individuals with heterozygous mutations in $\mathrm{IHH}$ in our cohort, which was significantly higher than that observed in a population study (12.1\%) (15). Four probands were born small for gestational age considering only length at birth. Affected subjects typically had mild disproportional short stature. The severity of short stature is variable and disproportionality seems to become more pronounced over the years.

\section{FGFR3}

The fibroblast growth factor receptor-3 (FGFR3) pathway acts as a negative regulator of the growth plate chondrogenesis (Figure 1). Heterozygous gain-offunction mutations in the FGFR 3 cause achondroplasia and hypochondroplasia. Achondroplasia is the most frequent skeletal dysplasia and is clinically characterized by severe disproportional short stature with rhizomelia (29). In contrast, hypochondroplasia is generally less severe and presents a broader phenotypic variability (30).

Although there is an evident abnormal proportion in patients with hypochondroplasia and FGFR 3 alterations 
is rare in patients classified as ISS (31), some children still can be undiagnosed at first evaluation. More recently, a study identified FGFR3-activating mutation causing autosomal dominant familial proportionate short stature without other specific findings (32).

\section{GENES RELATED TO THE GH-IGF1 AXIS}

Since the growth hormone $(\mathrm{GH})$ and insulin-like growth factor 1 (IGF-1) have been initially recognized as the main regulators of longitudinal growth, the first researches in the field of genetics of short stature attempted to identify children with defects in the GH-IGF-1-bone axis. GH is secreted by the pituitary gland, and promotes bone elongation mainly through regulating synthesis of IGF-1, both circulating and peripheral. Growth impairment can be caused by gene defects that affect several components of this cascade (summarized in Table 2), from the synthesis of GH to the action of IGF-1. Affected subjects may not present classical features of GH/IGF-1 deficiency or resistance, in which cases they would often be classified as having ISS.

\section{GH1}

Defects in $\mathrm{GHI}$ gene, which encodes GH, were firstly recognized as a cause of isolated GH deficiency (IGHD). The genetic defects responsible for this phenotype are generally deletions involving the gene or point mutations leading to a truncated protein, although some missense mutations and rare promoter region mutations have already been reported (33). Affected children typically present proportionate short stature with low growth velocity, low IGF-1 concentration and an inadequate response during $\mathrm{GH}$ provocative tests. Additionally, heterozygous and homozygous mutations in GHI have been associated with bioinactive GH, characterized by a similar phenotype to IGHD, except for normal or elevated GH levels (34).

Children with GHI defects may present a milder phenotype than that classically described, with no typical findings that allow the diagnosis of IGHD or of bioinactive GH. This may be particularly important in less severe genetic defects, as reported in a study that identified a heterozygous mutation in the GHI gene promoter associated to ISS (35). In these cases, the etiology of short stature remains undefined after the initial clinical and laboratorial evaluation.

\section{GHSR}

Two peptides stimulate GH synthesis and secretion: growth hormone-releasing hormone (GHRH) and ghrelin. Ghrelin acts through interaction with the GH secretagogue receptor (GHSR) and has also a potent orexigenic effect (36).

Defects in the GHSR gene have been associated with ISS and GH deficiency with variable severity and penetrance. Both phenotypes were even described in the same family (37). Additionally, some affected children had delayed puberty (38). This heterogeneity in clinical presentation may be partially explained because gene defects can result in protein alterations that affect the binding affinity to ghrelin and the constitutive activity of the receptor.

Table 2. Genes related to GH-IGF1 axis that are associated with isolated short stature

\begin{tabular}{|c|c|c|c|c|c|}
\hline Gene & $\begin{array}{l}\text { First report in patient } \\
\text { classified as ISS }\end{array}$ & Frequency in ISS (\%) & Inheritance & Additional common findings & References \\
\hline GH1 & 2003 & NA & $A D$ & Low height velocity and delayed bone age & (35) \\
\hline GHSR & 2006 & 2.0 to 2.4 & $\mathrm{AD} / \mathrm{AR}$ & GHD and ISS in the same family & $(37,55)$ \\
\hline GHR & 1995 & 0 to 5.0 & $A D$ & Laboratory suggestive of partial GH insensitivity & $(56,57)$ \\
\hline STAT5B & 2018 & NA & $A D$ & $\begin{array}{l}\text { Three families described with eczema and laboratory } \\
\text { suggestive of partial GH insensitivity }\end{array}$ & (41) \\
\hline IGF1 & 2012 & NA & $A D$ & Birth weight and birth length in the lower normal range & $(45,58)$ \\
\hline IGF1R & 2003 & 1.6 to 2.0 & $A D$ & $\begin{array}{l}\text { Born small for gestational age in the most cases and } \\
\text { elevated levels of IGF-1 }\end{array}$ & $(46,47,59)$ \\
\hline IGFALS & 2004 & NA & AR & $\begin{array}{l}\text { Severe deficiency of IGF-1 and IGFBP-3 } \\
\text { disproportional to the severity of short stature }\end{array}$ & (48) \\
\hline PAPP-A2 & 2016 & NA & AR & High levels of IGF-1 and IGFPB-3 & (50) \\
\hline
\end{tabular}

NA: prevalence study is not available; ISS: idiopathic short stature. 


\section{GHR}

$\mathrm{GH}$ exerts its action by binding to the $\mathrm{GH}$ receptor (GHR), a member of the cytokine superfamily of receptors. Homozygous or compound heterozygous mutations in GHR gene cause complete $\mathrm{GH}$ insensitivity (GHI), known as Laron syndrome, characterized by extreme short stature, high or normal GH concentrations, very low IGF-1 and IGFBP-3 levels, and no increase in IGF-1 concentration after exogenous GH stimulation (39). Differently, heterozygous GHR mutations can cause a variable spectrum of GHI, ranging from total absence of GHR activation to milder impairment causing subtler clinical phenotypes.

Until now, only seven patients have been reported with heterozygous GHR mutations with a dominantnegative effect causing short stature with recognizable features of partial GHI. Several other studies have reported heterozygous GHR variants in ISS patient cohorts, with a frequency between $5 \%$ and $15.5 \%$. However, many of these variants have not been proven to be causative of short stature. It is supposed that the ISS phenotype, accompanied by some degree of GHI, may be caused by less deleterious heterozygous GHR mutations. Some authors suggested that low growth hormone binding protein (GHBP) levels could indicate a defect in the extracellular domain of the GHR in these patients (40).

Hence, since the clinical characterization remains subjective, heterozygous GHR mutations may be responsible for the growth failure observed in a group of children with isolated short stature and non-classical laboratory phenotype associated with impaired GH action.

\section{STAT5B}

STAT5B is an essential protein in the intracellular signaling pathway downstream of GHR activation. Homozygous inactivating STAT5B mutations cause the classical phenotype of GH insensitivity associated with immunodeficiency (mainly eczema and chronic pulmonary disease). Relatives of autosomal recessive STAT5B deficient patients who carry STAT5B mutations usually have heights within the low normal range (41).

In 2018, three heterozygous STAT5B mutations with a dominat-negative effect were described in eleven individuals from three unrelated families, whose probands had undiagnosed short stature and laboratory evaluation of mild GH insensitivity. Most of the affected individuals presented elevated IgE, mild eczema and short stature with inter- and intra-familial variability (42).

\section{IGF1 and IGF1R}

IGF-1 is the main growth factor in intrauterine development and in postnatal growth and acts through the binding to a cell surface tyrosine kinase receptor called IGFIR. Deletions or homozygous loss-offunction mutations in IGFI gene cause severe pre- and post-natal growth failure, microcephaly and retarded intellectual development (43). Affected patients present extreme low IGF-1 levels with normal or high $\mathrm{GH}$ concentrations. Individuals heterozygous for IGFI variants were significantly shorter and had reduced head circumferences compared to noncarrier relatives. Affected children born from affected mothers appear to have a more compromised height, which suggest a role of placental dysfunction (44).

In 2014, a complete IGFI gene deletion in heterozygosity was reported in a patient with ISS. The affected child had birth length and weight within the low normal value and presented postnatal growth failure with low-normal serum IGF-1 (45).

Patients heterozygous for IGFRI defects have a similar phenotype to that of patients with IGF-I mutations, except for the relatively high IGF-1 concentrations (46). Although this is a rare condition, some patients may have a less obvious clinical presentation, and short statute may be the only recognizable characteristic (47).

\section{Ternary complex defects (IGFALS and PAPP-A2)}

Most of the serum IGF-1 circulates bound to IGF binding protein type 3 (IGFBP-3) and acid-labile subunit (ALS), forming a ternary complex. This complex is essential to extend serum IGF-l half-life and to decrease its bioavailability at tissue level. On the other hand, pregnancy-associated plasma protein A2 (PAPPA2) is a serum and tissue protease responsible for the proteolysis of IGFBP-3, releasing IGF-1 from the ternary complex.

Biallelic loss-of-function mutations in IGFALS result in extreme decrease in the circulating levels of functional ALS (48). The consequence of this is the impossibility to form a ternary complex with reduced IGF-1 and IGFBP-3 levels, which is reflected clinically 
in mild short stature associated with delayed puberty. Over the past years, it has been postulated that heterozygous variants in IGFALS are responsible for isolated short stature phenotype. Affected children presented partial ALS deficiency and a mean decrease in height of 1 SDS (49).

The opposite phenomenon, i.e. increased IGF-1 and IGFBP-3 levels, was first described in 2016. Five affected children coming from two different families had PAPPA2 deficiency caused by autosomal recessive mutations in PAPPA2 gene. In addition to variable short stature (heights ranged from -1.0 to -3.8 SDS), some patients had microcephaly, thin long bones, low bone mineral density, and insulin resistance (50).

\section{OTHER GENE}

\section{PTPN11}

The protein-tyrosine phosphatase non-receptor type 11 gene (PTPNII) encodes the non-receptor Srchomology 2 ( $\mathrm{SH} 2$ ) domain-containing protein tyrosine phosphatase 2 (SHP2). SHP2 participates in multiple intracellular signaling pathways, including the Ras/ MAPK cascade. Activating heterozygous mutations in PTPNII cause the Noonan syndrome (NS), characterized by reduced postnatal growth, congenital heart disease, and facial dysmorphisms. Commonly, affected children present low serum IGF-1 level, which reflects some degree of GH insensitivity (5l).

Similarly to the other genes reported above, there is a variable clinical presentation in affected individuals, even within the same family. In addition, the craniofacial features change with age, therefore it can be sometimes challenging to make a clinical diagnosis of NS. Finally, pathogenic variants in PTPNII have been identified in patients from a cohort of ISS children (11).

\section{CONCLUSION AND FUTURE DIRECTIONS}

Over the past several years, an increasing number of genetic variants have been associated with short stature. Many of these genes have been long known to be causing extreme phenotypes of growth disorders, which are clinically recognized, such as skeletal dysplasias or GH resistance syndromes. Nowadays, with the advent and greater availability of next-generation sequencing techniques, it has become possible to identify several gene defects in short stature children that presented clinically with the mildest spectrum of the diseases and that were initially classified as ISS.

The identification of the genetic causes of short stature prevents children to undergo unnecessary exams, and can give hints on the growth outcomes, with or without recombinant human $\mathrm{GH}$ ( $\mathrm{rhGH}$ ). For example, it is known that patients with $S H O X$ defects have a good response to rhGH therapy (18). Conversely, it is expected that ISS children with less severe defects of the GH-IGF-1 axis, including less severe GHR mutations, will respond less to rhGH use at regular dosage (40). Besides that, a CNP analog named vosoritide, that has been used as an experimental drug for the treatment of achondroplasia, can be in the future an option to treat children with nonsyndromic short stature, especially those with heterozygous mutations in the NPR 2 or in the NPPC genes (21).

The lack of specific characteristics makes accurate diagnosis difficult without the use of molecular genetic study. For this same reason, candidate gene analysis is generally not sufficient, and hence, a multiple-gene testing approach using next-generation sequencing (NGS) is preferable. The choice of the use of whole exome sequencing (WES) or gene-panel analysis of the genes will depend on the availability and on cost-benefit evaluation. Even when using the WES, the analysis of these patients should prioritize genes already associated with the isolated short stature phenotype. In the years that will follow, molecular genetic study using a panel of genes or exome analysis will become mandatory when investigating children with isolated short stature, with a crucial impact on treatment and follow-up.

Grants: this work was supported by Grants 2013/03236-5 (to A.A.L.J.) from the São Paulo Research Foundation (FAPESP), Grant 304678/2012-0 (to A.A.L.J.) from the National Council for Scientific and Technological Development (CNPq) and by the Coordenação de Aperfeiçoamento de Pessoal de Nivel Superior - Brasil (CAPES) - Finance Code 1658266 (to G.A.V.).

Disclosure: no potential conflict of interest relevant to this article was reported.

\section{REFERENCES}

1. Visscher PM. Commentary: Height and Mendel's theory: the long and the short of it. Int J Epidemiol. 2013;42(4):944-5.

2. Sisley S, Trujillo MV, Khoury J, Backeljauw P. Low incidence of pathology detection and high cost of screening in the evaluation of asymptomatic short children. J Pediatr. 2013;163(4):1045-51.

3. Cohen P, Rogol AD, Deal CL, Saenger P, Reiter EO, Ross JL, et al. Consensus statement on the diagnosis and treatment of children 
with idiopathic short stature: a summary of the Growth Hormone Research Society, the Lawson Wilkins Pediatric Endocrine Society, and the European Society for Paediatric Endocrinology Workshop. J Clin Endocrinol Metab. 2008;93(11):4210-7.

4. Silventoinen K, Sammalisto S, Perola M, Boomsma DI, Cornes BK, Davis $\mathrm{C}$, et al. Heritability of adult body height: a comparative study of twin cohorts in eight countries. Twin Res. 2003;6(5):399-408.

5. Wood AR, Esko T, Yang J, Vedantam S, Pers TH, Gustafsson S, et al. Defining the role of common variation in the genomic and biological architecture of adult human height. Nat Genet. 2014;46(11):1173-86.

6. Marouli E, Graff M, Medina-Gomez C, Lo KS, Wood AR, KjaerTR, et al. Rare and low-frequency coding variants alter human adult height. Nature. 2017;542(7640):186-90.

7. Eichler EE, Flint J, Gibson G, Kong A, Leal SM, Moore JH, et al. Missing heritability and strategies for finding the underlying causes of complex disease. Nat Rev Genet. 2010;11(6):446-50.

8. Grunauer M, Jorge AAL. Genetic short stature. Growth Horm IGF Res. 2018;38:29-33.

9. Dauber A, Stoler J, Hechter E, Safer J, Hirschhorn JN. Whole exome sequencing reveals a novel mutation in CUL7 in a patient with an undiagnosed growth disorder. J Pediatr. 2013;162(1):202-4 e1.

10. de Bruin C, Finlayson C, Funari MF, Vasques GA, Lucheze Freire B, Lerario AM, et al. Two Patients with Severe Short Stature due to a FBN1 Mutation (p.Ala1728Val) with a Mild Form of Acromicric Dysplasia. Horm Res Paediatr. 2016;86(5):342-8.

11. Wang SR, Carmichael H, Andrew SF, Miller TC, Moon JE, Derr $M A$, et al. Large-scale pooled next-generation sequencing of 1077 genes to identify genetic causes of short stature. J Clin Endocrinol Metab. 2013;98(8):E1428-37.

12. Rao E, Weiss B, Fukami M, Rump A, Niesler B, Mertz A, et al. Pseudoautosomal deletions encompassing a novel homeobox gene cause growth failure in idiopathic short stature and Turner syndrome. Nat Genet. 1997;16(1):54-63.

13. Vasques GA, Amano N, Docko AJ, Funari MF, Quedas EP, Nishi MY, et al. Heterozygous mutations in natriuretic peptide receptor-B (NPR2) gene as a cause of short stature in patients initially classified as idiopathic short stature. J Clin Endocrinol Metab. 2013;98(10):E1636-44.

14. Nilsson O, Guo MH, Dunbar N, Popovic J, Flynn D, Jacobsen $\mathrm{C}$, et al. Short stature, accelerated bone maturation, and early growth cessation due to heterozygous aggrecan mutations. J Clin Endocrinol Metab. 2014;99(8):E1510-8.

15. Vasques GA, Funari MFA, Ferreira FM, Aza-Carmona M, Sentchordi-Montane L, Barraza-Garcia J, et al. IHH Gene Mutations Causing Short Stature With Nonspecific Skeletal Abnormalities and Response to Growth Hormone Therapy. J Clin Endocrinol Metab. 2018;103(2):604-14.

16. Hisado-Oliva A, Ruzafa-Martin A, Sentchordi L, Funari MFA, Bezanilla-Lopez C, Alonso-Bernaldez $M$, et al. Mutations in C-natriuretic peptide (NPPC): a novel cause of autosomal dominant short stature. Genet Med. 2018;20(1):91-7.

17. Nilsson O, Marino R, De Luca F, Phillip M, Baron J. Endocrine regulation of the growth plate. Horm Res. 2005;64(4):157-65.

18. Marchini A, Ogata T, Rappold GA. A Track Record on SHOX: From Basic Research to Complex Models and Therapy. Endocr Rev. 2016;37(4):417-48

19. Jorge AA, Souza SC, Nishi MY, Billerbeck AE, Liborio DC, Kim CA, et al. SHOX mutations in idiopathic short stature and Leri-Weill dyschondrosteosis: frequency and phenotypic variability. Clin Endocrinol (Oxf). 2007;66(1):130-5.

20. Malaquias AC, Scalco RC, Fontenele EG, Costalonga EF, Baldin AD, Braz AF, et al. The sitting height/height ratio for age in healthy and short individuals and its potential role in selecting short children for SHOX analysis. Horm Res Paediatr. 2013;80(6):449-56.
21. Vasques GA, Arnhold IJ, Jorge AA. Role of the natriuretic peptide system in normal growth and growth disorders. Horm Res Paediatr. 2014;82(4):222-9.

22. Wang SR, Jacobsen $C M$, Carmichael $H$, Edmund $A B$, Robinson $\mathrm{JW}$, Olney RC, et al. Heterozygous mutations in natriuretic peptide receptor-B (NPR2) gene as a cause of short stature. Hum Mutat. 2015;36(4):474-81.

23. Gibson BG, Briggs MD. The aggrecanopathies; an evolving phenotypic spectrum of human genetic skeletal diseases. Orphanet J Rare Dis. 2016;11(1):86.

24. Gkourogianni A, Andrew M, Tyzinski L, Crocker M, Douglas $\mathrm{J}$, Dunbar N, et al. Clinical Characterization of Patients With Autosomal Dominant Short Stature due to Aggrecan Mutations. J Clin Endocrinol Metab. 2017;102(2):460-9.

25. van der Steen M, Pfundt R, Maas S, Bakker-van Waarde WM, Odink RJ, Hokken-Koelega ACS. ACAN Gene Mutations in Short Children Born SGA and Response to Growth HormoneTreatment. J Clin Endocrinol Metab. 2017;102(5):1458-67.

26. Minina E, Wenzel HM, Kreschel C, Karp S, Gaffield W, McMahon $A P$, et al. BMP and Ihh/PTHrP signaling interact to coordinate chondrocyte proliferation and differentiation. Development. 2001;128(22):4523-34.

27. Lai LP, Mitchell J. Indian hedgehog: its roles and regulation in endochondral bone development. J Cell Biochem. 2005;96(6):1163-73.

28. Liu M, Wang X, Cai Z, Tang Z, Cao K, Liang B, et al. A novel heterozygous mutation in the Indian hedgehog gene $(\mathrm{IHH})$ is associated with brachydactyly type A1 in a Chinese family. J Hum Genet. 2006;51(8):727-31.

29. Horton WA, Hall JG, Hecht JT. Achondroplasia. Lancet. 2007;370(9582):162-72.

30. Rousseau F, Bonaventure J, Legeai-Mallet L, Schmidt H, Weissenbach $\mathrm{J}$, Maroteaux $\mathrm{P}$, et al. Clinical and genetic heterogeneity of hypochondroplasia. J Med Genet. 1996;33(9):749-52.

31. Mamada M, Yorifuji T, Kurokawa K, Kawai M, Momoi T, Nakahata T. Prevalence of Mutations in the FGFR3 Gene in Individuals with Idiopathic Short Stature. Clin Pediatr Endocrinol. 2006;15(2):61-4.

32. Kant SG, Cervenkova I, Balek L, Trantirek L, Santen GW, de Vries $M C$, et al. A novel variant of FGFR3 causes proportionate short stature. Eur J Endocrinol. 2015;172(6):763-70.

33. Mullis PE. Genetics of growth hormone deficiency. Endocrinol Metab Clin North Am. 2007;36(1):17-36.

34. Besson A, Salemi S, Deladoey J, Vuissoz JM, Eble A, Bidlingmaier $M$, et al. Short stature caused by a biologically inactive mutant growth hormone (GH-C53S). J Clin Endocrinol Metab. 2005;90(5):2493-9.

35. Millar DS, Lewis MD, Horan M, Newsway V, Easter TE, Gregory JW, et al. Novel mutations of the growth hormone $1(\mathrm{GH} 1)$ gene disclosed by modulation of the clinical selection criteria for individuals with short stature. Hum Mutat. 2003;21(4):424-40.

36. Sun Y, Wang P, Zheng H, Smith RG. Ghrelin stimulation of growth hormone release and appetite is mediated through the growth hormone secretagogue receptor. Proc Natl Acad Sci U S A. 2004;101(13):4679-84.

37. Pantel J, Legendre M, Cabrol S, Hilal L, Hajaji Y, Morisset S, et al. Loss of constitutive activity of the growth hormone secretagogue receptor in familial short stature. J Clin Invest. 2006;116(3):760-8.

38. Pugliese-Pires PN, Fortin JP, Arthur T, Latronico AC, Mendonca $B B$, Villares SM, et al. Novel inactivating mutations in the GH secretagogue receptor gene in patients with constitutional delay of growth and puberty. Eur J Endocrinol. 2011;165(2):233-41.

39. Laron Z. Laron syndrome (primary growth hormone resistance or insensitivity): the personal experience 1958-2003. J Clin Endocrinol Metab. 2004;89(3):1031-44. 
40. Storr HL, Chatterjee S, Metherell LA, Foley C, Rosenfeld RG, Backeljauw PF, et al. Non-classical growth hormone insensitivity (GHI): characterization of mild abnormalities of GH action. Endocr Rev. 2018.

41. Scalco RC, Hwa V, Domene HM, Jasper HG, Belgorosky A, Marino $R$, et al. STAT5B mutations in heterozygous state have negative impact on height: another clue in human stature heritability. Eur J Endocrinol. 2015;173(3):291-6.

42. Klammt J, Neumann D, Gevers EF, Andrew SF, Schwartz ID, Rockstroh D, et al. Dominant-negative STAT5B mutations cause growth hormone insensitivity with short stature and mild immune dysregulation. Nat Commun. 2018;9(1):2105.

43. Woods KA, Camacho-Hubner C, Savage MO, Clark AJ. Intrauterine growth retardation and postnatal growth failure associated with deletion of the insulin-like growth factor I gene. N Engl J Med. 1996;335(18):1363-7.

44. van Duyvenvoorde HA, van Setten PA, Walenkamp MJ, van Doorn J, Koenig J, Gauguin L, et al. Short stature associated with a novel heterozygous mutation in the insulin-like growth factor 1 gene. J Clin Endocrinol Metab. 2010;95(11):E363-7.

45. Batey L, Moon JE, YuY, Wu B, Hirschhorn JN, ShenY, et al. A novel deletion of IGF1 in a patient with idiopathic short stature provides insight Into IGF1 haploinsufficiency. J Clin Endocrinol Metab. 2014;99(1):E153-9.

46. Abuzzahab MJ, Schneider A, Goddard A, Grigorescu F, Lautier C, Keller $\mathrm{E}$, et al. IGF-I receptor mutations resulting in intrauterine and postnatal growth retardation. N Engl J Med. 2003;349(23):2211-22.

47. Ester WA, van Duyvenvoorde HA, de Wit CC, Broekman AJ, Ruivenkamp CA, Govaerts LC, et al. Two short children born small for gestational age with insulin-like growth factor 1 receptor haploinsufficiency illustrate the heterogeneity of its phenotype. J Clin Endocrinol Metab. 2009;94(12):4717-27.

48. Domene HM, Bengolea SV, Martinez AS, Ropelato MG, Pennisi $P$, Scaglia $P$, et al. Deficiency of the circulating insulin-like growth factor system associated with inactivation of the acid-labile subunit gene. N Engl J Med. 2004;350(6):570-7.

49. Domene HM, Scaglia PA, Martinez AS, Keselman AC, Karabatas LM, Pipman VR, et al. Heterozygous IGFALS gene variants in idiopathic short stature and normal children: impact on height and the IGF system. Horm Res Paediatr. 2013;80(6):413-23.
50. Dauber A, Munoz-Calvo MT, Barrios V, Domene HM, Kloverpris S, Serra-Juhe $C$, et al. Mutations in pregnancy-associated plasma protein A2 cause short stature due to low IGF-I availability. EMBO Mol Med. 2016;8(4):363-74.

51. Tartaglia M, Kalidas K, Shaw A, Song X, Musat DL, van der Burgt $\mathrm{I}$, et al. PTPN11 mutations in Noonan syndrome: molecular spectrum, genotype-phenotype correlation, and phenotypic heterogeneity. Am J Hum Genet. 2002;70(6):1555-63.

52. Hu X, Gui B, Su J, Li H, Li N, YuT, et al. Novel pathogenic ACAN variants in non-syndromic short stature patients. Clin Chim Acta. 2017;469:126-9.

53. Hauer NN, Sticht H, Boppudi S, Buttner C, Kraus C, Trautmann $U$, et al. Genetic screening confirms heterozygous mutations in ACAN as a major cause of idiopathic short stature. Sci Rep. $2017 ; 7(1): 12225$.

54. Hellemans J, Coucke PJ, Giedion A, De Paepe A, Kramer P, Beemer $\mathrm{F}$, et al. Homozygous mutations in $\mathrm{IHH}$ cause acrocapitofemoral dysplasia, an autosomal recessive disorder with cone-shaped epiphyses in hands and hips. Am J Hum Genet. 2003;72(4):1040-6.

55. Inoue H, Kangawa N, Kinouchi A, SakamotoY, Kimura C, Horikawa $\mathrm{R}$, et al. Identification and functional analysis of novel human growth hormone secretagogue receptor (GHSR) gene mutations in Japanese subjects with short stature. J Clin Endocrinol Metab. 2011;96(2):E373-8.

56. Goddard AD, Covello R, Luoh SM, Clackson T, Attie KM, Gesundheit N, et al. Mutations of the growth hormone receptor in children with idiopathic short stature. The Growth Hormone Insensitivity Study Group. N Engl J Med. 1995;333(17):1093-8.

57. El Kholy M, Mella P, Rashad M, Buzi F, Meazza C, Zahra S, et al. Growth hormone/lGF-I axis and growth hormone receptor mutations in idiopathic short stature. Horm Res Paediatr. 2011;76(5):300-6.

58. Fuqua JS, Derr M, Rosenfeld RG, Hwa V. Identification of a novel heterozygous IGF1 splicing mutation in a large kindred with familial short stature. Horm Res Paediatr. 2012;78(1):59-66.

59. Caliebe J, Broekman S, Boogaard M, Bosch CA, Ruivenkamp CA, Oostdijk W, et al. IGF1, IGF1R and SHOX mutation analysis in short children born small for gestational age and short children with normal birth size (idiopathic short stature). Horm Res Paediatr. 2012;77(4):250-60. 